\title{
Retrospective analysis of single-center early and midterm results of transapical catheter-based mitral paravalvular leak closure with a purpose-specific device
}

\author{
Aleksejus Zorinas ${ }^{1}$, Vilius Janušauskas ${ }^{1}$, Giedrius Davidavičius ${ }^{1}$, Rokas Šimakauskas ${ }^{2}$, Lina Puodžiukaitè ${ }^{1}$, \\ Diana Zakarkaitè ${ }^{1}$, Valdas Bilkis ${ }^{1}$, Rasa Joana Čypienè ${ }^{1}$, Robertas Stasys Samalavičius ${ }^{3}$, \\ Eustaquio M. Onorato ${ }^{4}$, Audrius Aidietis ${ }^{1}$, Kęstutis Ručinskas ${ }^{1}$ \\ ${ }^{1}$ Clinic of Cardiac and Vascular Diseases, Faculty of Medicine, Vilnius University, Vilnius, Lithuania \\ ${ }^{2}$ Department of Pathology, Forensic Medicine and Pharmacology, Faculty of Medicine, Vilnius University, Vilnius, Lithuania \\ ${ }^{3}$ Center of Anaesthesiology, Intensive Care and Pain Management, Vilnius University Hospital Santaros Klinikos, Vilnius, Lithuania \\ ${ }^{4}$ Cardiovascular Department, Humanitas Gavazzeni, Bergamo, Italy
}

Adv Interv Cardiol 2018; 14, 2 (52): 167-175

DOI: https://doi.org/10.5114/aic.2018.76408

\begin{abstract}
A bstract
Introduction: Due to the recent lack of definitions to establish the severity of paravalvular leak (PVL) and endpoints for its treatment, the effectiveness and safety of a new device for PVL closure have not been comprehensively analyzed.

Aim: To analyze a single center's experience of mitral PVL closure in a surgical transapical catheter-based fashion with a purpose-specific device.

Material and methods: This is a retrospective cohort study of patients following transapical catheter-based mitral PVL closure with a purpose-specific device. Data were analyzed at baseline, perioperatively, at discharge, at six months and annually after the procedure.

Results: Nineteen patients underwent surgical transapical catheter-based mitral PVL closure with the Occlutech PLD Occluder. Mean follow-up time was $20 \pm 7$ (range: 9-33) months. The patients' mean age was $64 \pm 7$ years, and 11 (58\%) were male. Technical, device and individual patient success at follow-up was achieved in 18 (95\%), 16 (84\%) and 16 (84\%) patients respectively. Median intensive therapy unit stay was one day (1-4) and mean hospital stay was $11 \pm 4$ days. A reduction of paravalvular regurgitation to a mild or lesser degree was achieved in 18 (95\%) patients. There were no strokes or myocardial infarctions at follow-up. There were no deaths at 30 days after the procedure. One (5\%) patient expired due to progression of heart failure 12 months after surgery. None of the patients required immediate conversion to full sternotomy.

Conclusions: Surgical transapical catheter-based mitral PVL closure with the Occlutech PLD Occluder is a safe and clinically effective treatment.
\end{abstract}

Key words: heart failure, transcatheter closure, mitral regurgitation, paravalvular leak, prosthetic heart valve.

\section{Introduction}

In 1992 Hourihan et al. published the first clinical experience with catheter-based paravalvular leak (PVL) closure [1]. Since then various adjunctive devices have been used to treat heart failure and/or hemolytic anemia caused by mitral PVL: the Rashkind and Cuaso double umbrella device, Gianturco coils, Amplatzer Vascular Plug II and III, Amplatzer Duct Occluder, Amplatzer Septal Occluder, and the Muscular Ventricular Septal Defect Occluder were employed to occlude mitral paravalvular defects. Due to a lack of definitions to establish disease severity and endpoints for the safety and efficacy of PVL treatment there is currently an absence of outcomes for PVL treatment modalities in the literature [2]. Available data are very heterogeneous, with different devices being used, various access sites being employed for different valve prostheses, and mostly short-term outcomes are presented [3-5]. The specifically designed and manufactured Occlutech PLD Occluder for PVL closure has been introduced into clinical practice.

Corresponding author:

Aleksejus Zorinas MD, PhD, Clinic of Cardiac and Vascular Diseases, Faculty of Medicine, Vilnius University, 2 Santariskiu St, 04816 Vilnius, Lithuania, phone: +37 069829079, e-mail: aleksejus.zorinas@santa.lt

Received: 29.12.2017, accepted: 11.04.2018. 


\section{Aim}

The goal of this study is to analyze and report a single center's experience exclusively of the mitral PVL treatment in a surgical transapical catheter-based fashion with a purpose-specific device, 2 years after its implementation in clinical practice.

\section{Material and methods}

This is a retrospective cohort study. All patients who underwent surgical transapical catheter-based mitral valve PVL closure with a device specifically designed for paraprosthetic defects between April 2015 and April 2017 were included in the study. The study was approved by the Vilnius Regional Biomedical Research Ethics Committee and State Data Protection Inspectorate. All patients have read and signed the informed consent form.

Following initial diagnosis established by transthoracic echocardiography, the shape, size and location of the defect were detailed using 3-dimensional transesophageal echocardiography (3D TEE). The location of the PVL was described in a clock-like fashion [6]. The degree of paravalvular regurgitation was evaluated with 3D TEE color Doppler and determined according to the unifying five-class scheme for PVL regurgitation severity [2, 7]. All patients were assessed and discussed for the treatment modality at a heart team multidisciplinary meeting. Indications for the procedure were significant mitral PVL in patients with symptoms of heart failure, symptomatic hemolytic anemia (hemoglobin less than $100 \mathrm{~g} / \mathrm{l}$ or patients requiring red blood cell transfusions and all other reasons for anemia were excluded) or a combination of both [8]. Contraindications for the procedure were active prosthetic infective endocarditis and/or significant dehiscence of the mitral prosthesis (more than $1 / 3$ of the prosthesis annular perimeter).

The patients' data were analyzed at baseline, perioperatively, at discharge, at 6 months and annually after the procedure. The prosthetic valve function and residual degree of regurgitation at follow-up were evaluated using transthoracic echocardiography. 3D TEE at follow-up was performed in selected patients when the quality of transthoracic echocardiography was not sufficient.

Primary endpoints after treatment were the absence of mortality, of moderate or severe residual regurgitation, of new or worsening hemolysis, of new or worsening prosthesis dysfunction, of conversion to open surgery, of stroke and readmission for heart failure or treatment of hemolytic anemia [2]. Secondary endpoints were the absence of acute kidney injury (creatinine increase 150\% compared with the baseline), and bleeding according to the BARC criteria [9]. Acute kidney injury was assessed in accordance with the KDIGO clinical practice guidelines [10].

The continued intended safety and performance of the device were evaluated by the absence of occluder migration, embolization, detachment, fracture, worsening of hemolysis, or systemic emboli related to device thrombosis, erosion of bioprosthetic leaflet or surrounding tissue, transvalvular gradient increase by more than $10 \mathrm{~mm} \mathrm{Hg}$, reduction of paravalvular insufficiency without producing central valvular incompetence or stenosis [2].

A 6-minute walk test was used to assess the individual patient success of those who presented with heart failure symptoms. A quality of life assessment was not performed.

\section{Statistical analysis}

Statistical analysis was performed using the data acquisition and analysis software package SPSS 21.0 (IBM Corp., Armonk, NY, USA). The quantitative normality of continuous data was evaluated using the criteria of histograms, rectangular diagrams, and the Shapiro-Wilk test $(p>0.05)$. Quantitative data, distributed as a normal curve, are presented as a mean value \pm standard deviation. Quantitative continuous data not following a normal distribution are presented as the median and quartile intervals. Categorical data are expressed as percentages. Freedom from moderate or severe residual paravalvular regurgitation, new or worsening hemolysis requiring transfusion, new or worsening prosthesis dysfunction and conversion to open surgery, mortality, stroke, readmission for heart failure or treatment of hemolytic anemia was estimated using the Kaplan-Meier method. The censored data include patients who had the follow-up terminated. A $p$-value $<0.05$ was considered as statistically significant.

\section{Procedure description}

The procedure is carried out in a hybrid operating room. Standard cardiac monitoring for adult redo surgery is applied. Prior to the skin incision transthoracic echocardiography is performed to identify the location of the apex. Left anterolateral thoracotomy is performed at the apex of the left ventricle, and the pericardium is opened. Dissection of the adhesions is performed. Stay sutures are placed on the edges of the pericardium and hinged to the skin. Two "U" shape sutures reinforced with pledgets are placed and secured with the tourniquets at the apex of the heart. After the administration of heparin a needle puncture of the left ventricle is performed and the guide wire is introduced with a subsequent short catheter sheath insertion.

Real-time 3D TEE is performed to identify and confirm the exact location, detailed size, depth and shape of the PVL. A hydrophilic guide wire is used to pass through the defect with the help of a multipurpose catheter. The fusion of real-time 3D TEE and fluoroscopy imaging may be used to ease the passage through the defect [11]. The guiding catheter is advanced through the leak and the hydrophilic guide wire is replaced with stiff wire. A delivery sheath is chosen according to the manufacturer's recommendations. The guiding catheter is removed and 
the delivery sheath is advanced through the defect. The device is deployed under control of real-time 3D TEE and fluoroscopy. Following full expansion of both the proximal and distal discs, the function of the prosthetic valve is checked for its interference with the occluder. If performance of the valve prosthesis is not compromised, and paravalvular regurgitation is significantly reduced or not present, the device is detached from the delivery system.

Following successful PVL closure, catheters and sheaths are removed, and protamine sulfate administered. " $U$ " shape sutures are securely tightened and the pericardium is closed. The pleural cavity is drained with one drain, and then the thoracotomy is closed. The patients are transferred to the cardiac intensive therapy unit.

\section{Translation of the PVL dimensions into the occluder}

As dimensions of the defect may change over time, occluder selection is made during the procedure. The choice is made in accordance with the dimensions of the PVL channel length and cross sectional area, established following multi-planar reconstruction of the 3D TEE data set. The specific occluder for PVL closure comes in two shapes, Waist and Twist. Our opinion does not diverge from other authors: the Waist type of the device should be chosen for oblong or crescent shape shallow defects. To prevent the occluder from bending or folding after deployment in the defect, it should not be oversized in comparison to cross sectional measurements of the defect $[5,12]$. Bending or folding of it may cause significant residual regurgitation. The Twist type should be employed for defects which are oval and/or "deeply" channeled. In an ideal scenario, the disc connecting part should have a snug fit to the defect, and thus has to match or be as close as possible to the defect cross sectional measurements. In the case of failure to occlude complex defects with a single plug, a multiple plug approach should be attempted [13].

\section{Results}

In April 2015 the Occlutech PLD Occluder was introduced into clinical practice at our institution. Up to April 2017 nineteen patients underwent surgical transapical catheter-based mitral PVL closure with this device. No patients were lost to follow-up. All patients have completed the planned follow-up. Mean follow-up time was $20 \pm 7$ (range: 9-33) months.

\section{Clinical characteristics of the population treated}

There were 19 patients; mean age was $64 \pm 7$ years, 11 (58\%) were male. Eighteen (95\%) patients were treated electively. Mean time from the mitral valve replacement was $3.6(1.1-15)$ years. Four (21\%) patients previously had failed surgery for mitral paravalvular regurgitation. Almost two thirds of the patients presented with NYHA class III symptoms. One-third of the patients (35\%) were anemic (hemoglobin concentration < $100 \mathrm{~g} / \mathrm{l}$ ). Perioperative risk for mortality according to the EuroSCORE was 5.7\% (3.5-9.3\%) [14]. Mean glomerular filtration rate was 75 (67-91) $\mathrm{ml} / \mathrm{min}$. Eight (42\%) patients had moderately abnormal (LVEF $\geq 30 \%<45 \%), 2$ (11\%) patients mildly abnormal (LVEF $\geq 45 \%<55 \%$ ) and 9 (47\%) had good (LVEF $\geq 55 \%$ ) left ventricle systolic function. Pulmonary artery pressure above $55 \mathrm{~mm} \mathrm{Hg}$ was observed in 8 (42\%) patients. Ten (53\%) patients presented only with symptoms of heart failure, $2(11 \%)$ only with symptoms of hemolytic anemia and 7 (36\%) with a combination of both. In 15 (79\%) patients a single mitral paravalvular defect was diagnosed, 3 (16\%) had two leaks and in $1(5 \%)$ patient three defects were detected. Moderate paravalvular regurgitation was found in $3(16 \%)$ patients, while 16 (84\%) patients had severe regurgitation. Patient characteristics are presented in Table I.

\section{Morphological and topographic description of} the paravalvular defects

There were 24 defects in 19 patients. Seventeen (71\%) leaks were oval, and 7 (29\%) were crescent shaped. Paravalvular defects were distributed evenly alongside the perimeter of the mitral valve annulus. Twelve (50\%) were at the anterior while 11 (46\%) were at the posterior leaflet aspects of the mitral valve and $1(4 \%)$ defect was at the medial commissure (A3/P3). One-third of the PVL defects were at the central posterior aspect (P2) of the mitral annulus. The PVL distribution is presented in Table II and Figure 1.

\section{Mortality}

There was no immediate procedural mortality, nor did death occur at 30, 60 and 90 days of the follow-up. Due to progressive heart failure 1 patient expired 12 months after the procedure. This was the only patient with ineffectively occluded PVL.

\section{Technical success}

There were no periprocedural strokes. All devices were successfully delivered and positioned, the delivery systems were withdrawn with no complications, and no periprocedural impingement between the device and mitral valve prosthesis occurred. There was no immediate conversion to full sternotomy. A failure to reduce PVL to a mild or lesser degree occurred in 1 patient; otherwise, technical success was achieved in 18 (95\%) cases.

\section{Description of the patient with failed reduction} of paravalvular regurgitation

A 60-year old woman underwent mitral replacement with a bi-leaflet mitral prosthesis 32 years ago. The patient failed previous redo surgery for PVL twice. As mitral PVL persisted, she was referred for a surgical transapical 
Table I. Detailed patient clinical characteristics

\begin{tabular}{|c|c|}
\hline Clinical variables & $\begin{array}{c}N(\%) / \\
\text { median (Q1-Q3) }\end{array}$ \\
\hline Number of patients & 19 \\
\hline Age [years] & $64 \pm 7$ \\
\hline Gender, male & $11(58)$ \\
\hline Presentation, elective & $18(95)$ \\
\hline Time since primary procedure [years] & $3.6(1.1-15)$ \\
\hline Previous PVL surgical closure & $4(21)$ \\
\hline \multicolumn{2}{|l|}{ NYHA: } \\
\hline$\|$ & $5(26)$ \\
\hline III & $11(58)$ \\
\hline IV & $3(16)$ \\
\hline EUROSCORE II & $5.7(3.5-9.3)$ \\
\hline Diabetes mellitus & $4(20)$ \\
\hline Hemolysis & $7(41)$ \\
\hline Serum LDH concentration [U/I] & $355(317-584)$ \\
\hline Serum LDH concentration $>360 \mathrm{U} / \mathrm{I}$ & $9(47)$ \\
\hline Anemia $<100 \mathrm{~g} / \mathrm{l}$ & $6(35)$ \\
\hline Serum creatinine concentration $[\mu \mathrm{mol} / \mathrm{l}]$ & $91(74-110)$ \\
\hline Serum creatinine concentration $>200 \mu \mathrm{mol} / \mathrm{l}$ & $1(5)$ \\
\hline \multicolumn{2}{|l|}{ Glomerular filtration rate: } \\
\hline GFR $\mathrm{ml} / \mathrm{min}$ & 75 (67-91) \\
\hline GFR $<51 \mathrm{ml} / \mathrm{min}$ & $3(16)$ \\
\hline GFR $<85 \mathrm{ml} / \mathrm{min}$ & $14(84)$ \\
\hline \multicolumn{2}{|l|}{ Left ventricle function: } \\
\hline Severely abnormal (LVEF <30\%) & $0(0)$ \\
\hline Moderately abnormal $(30 \% \leq \mathrm{LVEF}<45 \%)$ & $8(42)$ \\
\hline Mildly abnormal (45\% $\leq$ LVEF < 55\%) & $2(11)$ \\
\hline Good (LVEF $\geq 55 \%)$ & $9(47)$ \\
\hline Pulmonary artery pressure $>55 \mathrm{~mm} \mathrm{Hg}$ & $8(42)$ \\
\hline \multicolumn{2}{|l|}{ Prosthetic valve type: } \\
\hline Bioprosthesis & $3(16)$ \\
\hline Mechanical & $14(74)$ \\
\hline Annuloplasty ring & $2(11)$ \\
\hline \multicolumn{2}{|l|}{ Indications for PVL closure: } \\
\hline Hemolytic anemia & $2(11)$ \\
\hline Heart failure & $10(53)$ \\
\hline Both & $7(36)$ \\
\hline \multicolumn{2}{|l|}{ Number of PVL per patient: } \\
\hline 1 defect & $15(63)$ \\
\hline 2 defects & $3(16)$ \\
\hline 3 defects & $1(5)$ \\
\hline \multicolumn{2}{|l|}{ Degree of PVL regurgitation: } \\
\hline Moderate & $3(16)$ \\
\hline Severe & $16(84)$ \\
\hline
\end{tabular}

EuroSCORE - European System for Cardiac Operative Risk Evaluation, GFR glomerular filtration rate, $L D H$ - lactate dehydrogenase, $L V E F$ - left ventricular ejection fraction, NYHA - New York Heart Association heart failure classification system, PVL - paravalvular leak.
Table II. Morphological and topographic description of the paravalvular defects

\begin{tabular}{lc} 
Paravalvular leak characteristics & $\mathbf{N}(\%) /$ median (Q1-Q3) \\
\hline Number of PVLs & 24 \\
\hline PVL location: & $6(26)$ \\
\hline A1 & $6(26)$ \\
\hline A3 & $1(4)$ \\
\hline A3/P3 & $1(4)$ \\
\hline P1 & $8(36)$ \\
\hline P2 & $2(8)$ \\
\hline P3 & $4(17)$ \\
\hline Complex PVL (defect with suture) & $7(29)$ \\
\hline PVL shape: & $17(71)$ \\
\hline Crescent & $4(4-10)$ \\
\hline Oval & \\
\hline PVL size [mm]: & \\
\hline Length & \\
\hline Width & \\
\hline
\end{tabular}

PVL - paravalvular leak.

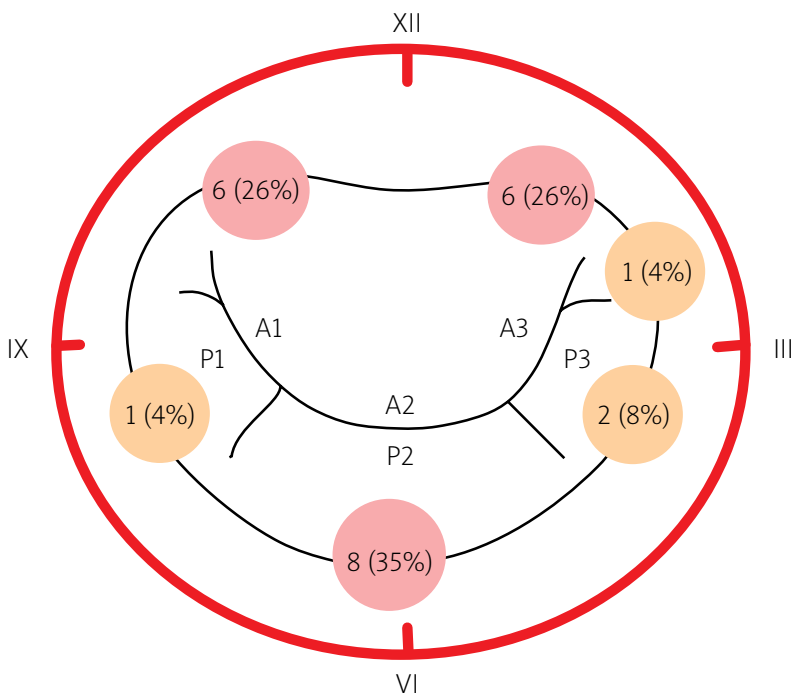

Figure 1. Distribution of PVLS along perimeter of mitral valve, presented in clock-like fashion (6). III, VI, IX and XII - hours of the clock; A1, A2, A3, P1, P2, P3 - mitral valve scallops (segments). 1 (4\%), 2 (8\%), 6 (26\%), 8 (35\%) - number of defects and percentage in our cohort of patients 
catheter-based procedure. She was suffering from heart failure and anemia. 3D TEE showed the defect at the P2 aspect of the mitral annulus (dimensions were $4 \times 10 \mathrm{~mm}$, crescent in shape with surgical suture crossing the defect in the middle). Multiple attempts to deploy occluders of various sizes and shapes were undertaken. The best intraoperative result was achieved with the combination of $4 \times 2 \mathrm{~mm}$ rectangular waist and $4 \times 4 \mathrm{~mm}$ square plugs with moderate residual regurgitation. Unfortunately, severe paravalvular regurgitation was present at discharge. She was referred for redo surgery again. The plan was abandoned because of severe pulmonary hypertension, severe tricuspid regurgitation, poor kidney function, chronic lung disease treated with bronchodilators and a history of two unsuccessful redo mitral valve replacement procedures (EuroSCORE II - 19.4\%). The patient expired due to the progression of heart failure 12 months after unsuccessful PVL closure.

\section{Device success (early and at follow-up)}

No occluder migration, detachment, fracture, embolization due to thrombosis or endocarditis occurred. Device success was achieved in 16 (84\%) patients. Failure to treat PVL occurred in 1 patient (described above). In another patient, PVL was reduced from severe to mild. Unfortunately, worsening anemia developed requiring transfusion of four units of red blood cells weekly. This patient underwent redo surgery with occluder removal and prosthesis replacement. The third patient had excessive postoperative bleeding requiring surgical revision.

\section{Description of a patient with worsened anemia}

A 57-year-old man with a previous history of moderate aortic stenosis developed infective endocarditis with an abscess on the aortic mitral curtain. He underwent uneventful replacement of both valves with a bi-leaflet mechanical prosthesis. Two months after surgery he presented with severe hemolytic anemia. 3D TEE revealed a mitral PVL. The defect was $8 \times 5 \mathrm{~mm}$ at 2 o'clock (A3), oval shape, causing severe regurgitation. Another defect, $2 \mathrm{~mm}$ in diameter, was at 6 o'clock (P2), and causing trivial regurgitation. The patient underwent a surgical transapical catheter-based mitral PVL closure procedure. An attempt to close the defect with a $8 \times 4 \mathrm{~mm}$ (61 PLD 08 Waist) device failed to reduce regurgitation. A significant reduction of regurgitation was achieved with a $12 \times 5 \mathrm{~mm}$ (61 PLD 12 Waist) rectangular occluder. Real-time 3D TEE showed the presence of mild regurgitation located next to the device. No impingement of the occluder with the prosthesis or incomplete expansion of the discs was observed. The defect at 6 o'clock was considered too small and was left intact. As the treatment result was acceptable, a team decision to terminate the procedure was made. Although PVL regurgitation was reduced from severe to mild, the patient developed worsening anemia on the seventh postoperative day, requiring transfusion of four units of red blood cells weekly. All other possible causes of anemia were excluded. Despite a high perioperative risk, he underwent redo surgery with removal of the PVL closure device and both mechanical aortic and mitral prosthesis replacement with tissue prosthesis and was discharged from hospital on the $40^{\text {th }}$ postoperative day.

\section{Procedural success (early)}

All patients were discharged from hospital. Median intensive therapy unit stay was 1 (1-4) day, and mean hospital stay was $11 \pm 4$ days. Complete closure of the mitral PVL intraoperatively and at discharge (no or trivial residual paravalvular regurgitation) was achieved in 14 (74\%) patients, a reduction to mild in $4(21 \%)$ patients; in $1(5 \%)$ patient a reduction of paravalvular regurgitation was not achieved. A reduction of paravalvular regurgitation to a mild or lesser degree was achieved in 18 (95\%) patients. Six-minute walk distance increased from 264 $\pm 108 \mathrm{~m}$ on admission to $313 \pm 120 \mathrm{~m} \mathrm{(} p=0.02,95 \% \mathrm{Cl}$ : 20-77) 30 days after the procedure. Relief from anemia was achieved in 7 (78\%) out of 9 patients.

\section{Individual patient success (1-year follow-up)}

Individual patient success at 1-year follow-up was achieved in 16 (84\%) patients treated (failure to reduce mitral paravalvular regurgitation in 1 patient, worsened anemia in another and severe bleeding from a fractured rib in the third patient).

\section{Bleeding}

Postoperatively in the first $24 \mathrm{~h}$ after the procedure median blood loss was $100(75-180) \mathrm{ml}$, ranging from $50 \mathrm{ml}$ to $1450 \mathrm{ml}$. One patient bled $1450 \mathrm{ml}$ in the first $24 \mathrm{~h}$ (BARC type $3 \mathrm{~b}$ ), and required re-exploration. Another patient bled due to a heparin overdose and lost $500 \mathrm{ml}$ of blood in the first $24 \mathrm{~h}$ (BARC type $3 \mathrm{a}$ ) and was managed medically. In 3 patients postoperative bleeding was BARC type 2 and they were treated with packed red blood cell transfusions. A total of 5 (26\%) patients bled in accordance with the BARC criteria. No deaths due to bleeding occurred. No bleeding events occurred at follow-up after discharge.

\section{Description of the patient requiring surgical exploration}

A 75-year-old man presented with symptoms of heart failure due to mitral PVL. The 3D TEE has confirmed presence of a crescent-shaped paravalvular defect at the $\mathrm{A} 3 \mathrm{as}$ pect of the mitral annulus with dimensions of $10 \times 4 \mathrm{~mm}$. He underwent surgical transapical catheter-based mitral PVL uneventful closure. In the fourth postoperative hour, immediately after extubation, the patient lost $1000 \mathrm{ml}$ of 
Table III. Immediate postoperative data and complications

\begin{tabular}{|c|c|}
\hline Clinical variables & $\begin{array}{c}N(\%) / \\
\text { median (Q1-Q3) }\end{array}$ \\
\hline Number of patients & 19 \\
\hline $\begin{array}{l}\text { Immediate procedural mortality } \\
\text { ( } \leq 72 \mathrm{~h} \text { after the procedure) }\end{array}$ & $0(0)$ \\
\hline $\begin{array}{l}\text { Procedural mortality } \\
\text { (all-cause mortality } 30 \text { days or in-hospital) }\end{array}$ & $0(0)$ \\
\hline $\begin{array}{l}\text { Myocardial infarction } \\
\text { ( } \leq 72 \mathrm{~h} \text { after the procedure) }\end{array}$ & $0(0)$ \\
\hline $\begin{array}{l}\text { Myocardial infarction } \\
\text { (within } 30 \text { days or in-hospital) }\end{array}$ & $0(0)$ \\
\hline $\begin{array}{l}\text { Stroke (within } 30 \text { days or during procedure } \\
\text { hospitalization) }\end{array}$ & $0(0)$ \\
\hline \multicolumn{2}{|l|}{ Acute kidney injury: } \\
\hline Stage 1 ( $\mathrm{SCr}^{\mathrm{c}}$ increased 1.5-2 times baseline) & $2(11)$ \\
\hline Stage 2 ( $\mathrm{SCr}^{\mathrm{c}}$ increased $2-3$ times baseline) & $3(16)$ \\
\hline $\begin{array}{l}\text { Stage } 3 \text { ( } \mathrm{SCr} \mathrm{r}^{c} \text { increased }>3 \text { times baseline } \\
\text { or RRT) }\end{array}$ & $0(0)$ \\
\hline \multicolumn{2}{|l|}{ Bleeding according to BARC: } \\
\hline $\begin{array}{l}\text { Life-threatening or disabling bleeding } \\
\text { (type 5, 3b and 3c) }\end{array}$ & $0(0)$ \\
\hline Major bleeding (type 3a) & $1(5)$ \\
\hline $\begin{array}{l}\text { Minor bleeding (type } 2 \text { or } 3 a \text {, depending on } \\
\text { the severity) }\end{array}$ & $1(5)$ \\
\hline None & $17(89)$ \\
\hline \multicolumn{2}{|l|}{ Access site complications: } \\
\hline Major access site complications & $1(5)$ \\
\hline Minor access site complications & $0(0)$ \\
\hline No access site complications & $18(95)$ \\
\hline \multicolumn{2}{|l|}{ Conduction disturbances and arrhythmias: } \\
\hline $\begin{array}{l}\text { New or worsened cardiac arrhythmia or } \\
\text { conduction disturbance }\end{array}$ & $1(5)$ \\
\hline New permanent pacemaker implantation & $0(0)$ \\
\hline Surgical revision & $1(5)$ \\
\hline \multicolumn{2}{|l|}{ Reason for revision: } \\
\hline DSWI & $0(0)$ \\
\hline Heart failure & $0(0)$ \\
\hline Bleeding & $1(5)$ \\
\hline Wound infection & $0(0)$ \\
\hline Sepsis & $0(0)$ \\
\hline Drainage [ml/day] & $100(100-200)$ \\
\hline Prolonged ventilation & $0(0)$ \\
\hline Hospital stay [days] & $10(9-13)$ \\
\hline Intensive therapy unit stay [days] & $1(1-1)$ \\
\hline
\end{tabular}

DSWI - deep sternal wound infection, RRT - renal replacement therapy, $\mathrm{SCr}$ - serum creatinine concentration.

blood. Emergency revision was performed. The bleeding source was rib fracture, possibly caused by the rib retractor blade. The patient's further postoperative course was uneventful.

\section{Acute kidney injury}

Mean preoperative creatinine was 91 (74-110) $\mu \mathrm{mol} / \mathrm{l}$; mean postoperative creatinine was 105 (85-155) $\mu \mathrm{mol} / \mathrm{l}$ $(p=0.07)$. In accordance with the KDIGO clinical practice guidelines, stage 1 acute kidney injury occurred in 5 (26\%) patients, and stage 2 occurred in 1 patient (5\%); none of the patients developed acute kidney injury at stage 3 and none required renal replacement therapy.

Immediate postoperative data and complications in detail are presented in Table III.

\section{Access-site related complications}

An access site related complication occurred in 1 (5\%) patient, due to a surgical retractor blade injury to the rib with subsequent severe bleeding requiring surgical revision. There was no wound infection in accordance with the ASEPSIS scoring system or CDC definitions of nosocomial surgical site infections $[15,16]$.

\section{Discussion}

Until the recent development and widespread use of catheter-based closure procedures for PVL, repeat surgical treatment was the only effective treatment modality $[17,18]$. Despite its improved survival compared with conservative management, redo surgery for mitral paravalvular defects may carry high morbidity and mortality. Also a high rate of reoccurrence of this complication is noted $[17,19,20]$. The high rate of mortality and morbidity following conventional redo surgery, the burden of complicated postoperative care and the rapid development of various catheter-based intracardiac procedures have driven medical professionals together with the medical industry to introduce into clinical practice a less invasive treatment modality possibly carrying better outcomes - catheter-based PVL closure.

Recently a new device (Occlutech PLD Occluder, Occlutech, Jena, Germany) for PVL closure has been developed and introduced into clinical practice. To date, only a few studies of mitral PVL treated by the surgical transapical catheter-based approach have been published [21-23].

In early 2013 at Vilnius University Hospital Santaros Klinikos, catheter-based mitral PVL closure with an off-label device was introduced into practice. Our choice of access site was determined by the evidence in the literature where the authors have demonstrated low incidence of adverse procedural events compared with other closure methods. For this reason some conclude that the transapical approach could be considered as a first line therapy $[23,24]$. Other authors state that this approach allows access to defects in all anatomic locations of the mitral prosthesis [3]. Furthermore, the analysis by Jelnin et al. showed that a planned transapical approach resulted in shorter fluoroscopy and procedural times compared with the converted and combined trans-septal procedures [25]. Also, at the time of the initiation of the 
catheter-based treatment of paravalvular regurgitation at our center the transapical procedure to correct mitral regurgitation was already in full swing [26]. This experience was easily translated into the mitral PVL closure procedure. The open surgical transapical approach was also chosen for the reasons of controlled surgical closure of the ventricular puncture and avoidance of damage to the coronary arteries. Consistent with other investigators we found that this access site provides a high rate of mitral PVL closure and also is practical and feasible.

We began to use the Occlutech PLD Occluder at the beginning of 2015 a few months after the European CE mark approval. Each paravalvular defect is unique in shape, geometry, size and its proximity to the prosthesis. To fit such a wide variety of defects the manufacturer offers Occlutech PLD devices in various sizes and shapes. Oblong devices may fit the defect more accurately, and in the paper by Calvert et al. it was associated with less leakage and more improved heart failure symptoms at follow-up [3].

Technical success of patients treated in transapical fashion for mitral PVL closure may vary from $91 \%$ to $100 \%$ [22, 27-29]. In our group it was achieved in 18 (95\%) patients. Failure to reduce mitral PVL in 1 (5\%) patient occurred due to the tortuous anatomy of the defect (crescent shape with surgical suture material crossing it in the middle). Retrospectively analyzing the periprocedural events of these particular patients, it could have been helpful to attempt to implant two small square occluders in the Hopscotch technique fashion [30].

We found almost no reports in the recent literature where device success of catheter-based mitral PVL clo-

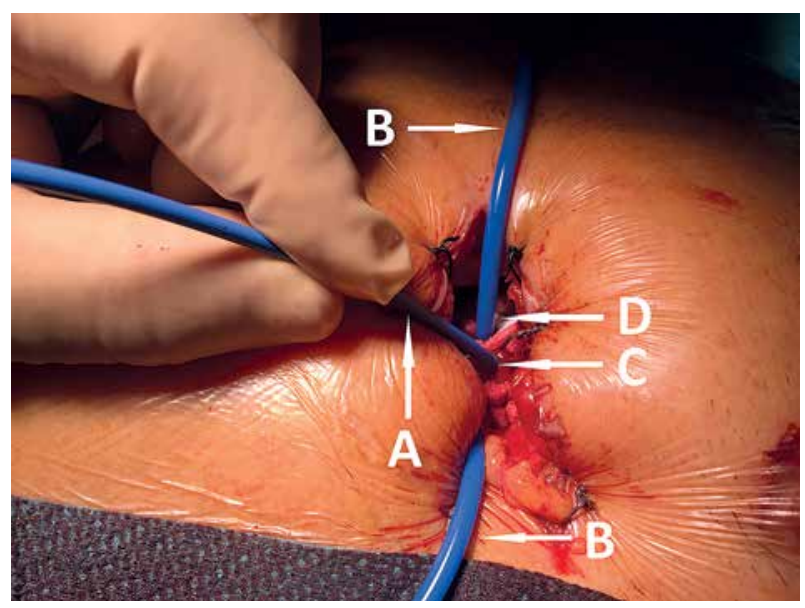

Figure 2. A - Delivery catheter introduced in to the left ventricle. B - Tourniquets securing the " $U$ " shape sutures at the apex of the heart. C - Entry site of the delivery catheter into the left ventricle. $D$ - "U" shape sutures reinforced with pledgets on the apex of the left ventricle

sure is presented as recommended by the recent expert statement [2]. Device success in our group at 30 days and follow-up was achieved in 16 (84\%) patients, compared to the rate of $83 \%$ presented recently by Aydin et al. (due to the reduction of paravalvular regurgitation to a mild degree or none in 10 patients out of 12 and the absence of other complications) or $86 \%$ reported by Smolka et al., making our device success rate similar to the results reported previously [22].

We failed to achieve device success in 3 patients due to the impossibility of reducing paravalvular regurgita-

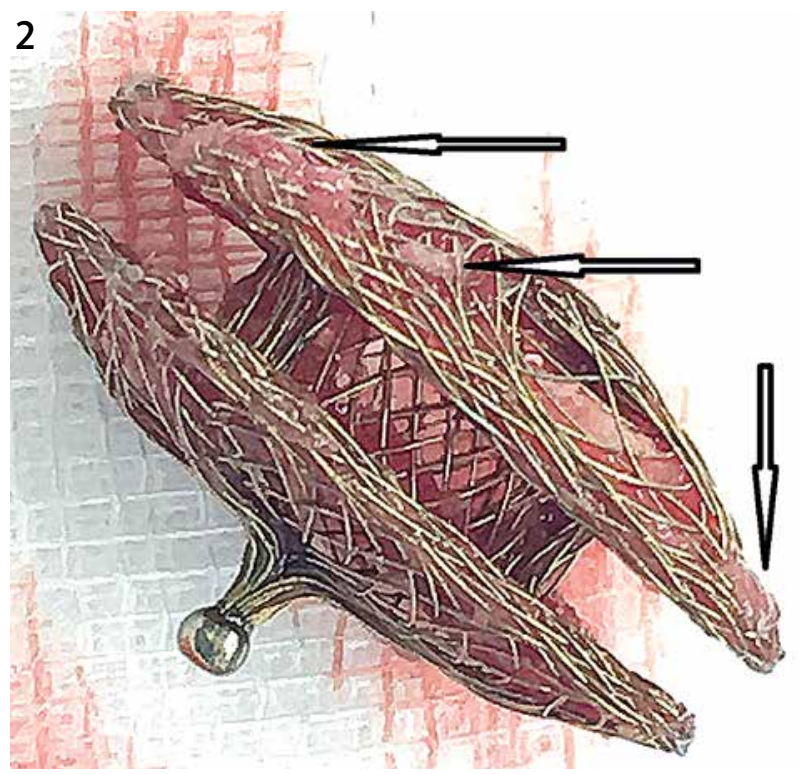

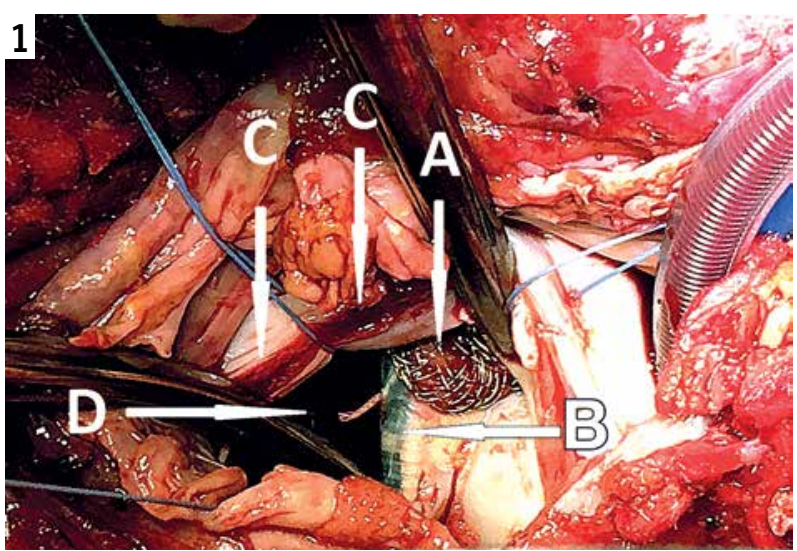

Figure 3. Intraoperative pictures of the PLD occluder in patient with worsened anemia. 1: PLD occluder at the A2 aspect of the mitral valve annulus. A - PLD occluder in situ at the A2 aspect of the mitral valve annulus, $B$ - cuff of the mitral valve prosthesis, C - interatrial septum, D - left atrium. 2: PLD occluder removed. Arrows point to scarce "islands" of epithelium 
tion in 1 patient, a bleeding event in another and worsened anemia in the third (described in detail above). A bleeding event occurred in a frail octogenarian due to the use of a rigid metallic Finochietto rib retractor and overspread of the intercostal space; this caused rib fracture and damage to the intercostal neurovascular bundle $[31,32]$. Some authors promote avoidance of rib fracture during the thoracotomy due to the potential for postoperative chest wall hemorrhage or hemothorax [31, 33]. Potentially, with the use of the atraumatic plastic soft tissue retractors the rate of bleeding due to trauma to the ribs can be avoided. Unfortunately, due to the additional cost to the procedure, we are very limited in use of additional "expensive" materials such as a soft tissue retractor. To minimize the risk of rib fracture with consequent bleeding we limited the use of a rigid Finochietto retractor only to pericardial adhesion dissection and its hitching to the skin; later, for the entire procedure we removed the rib spreader (Figure 2).

The failure to treat hemolysis in one of our patients despite PVL reduction to a mild degree has also been described by Smolka et al. and other authors [5, 34]. The understanding of the hemolysis mechanism in those patients is difficult. As stated by Kliger et al., some patients after catheter-based PVL closure continue to be transfusion-dependent, as hemolysis can occur from blood shunting through the device and typically should resolve within 6 months after complete endothelialization [35]. Exacerbation of hemolytic anemia may have happened due to the device being oversized in comparison to the defect, which later led to its bending and residual mild regurgitation. Following this experience found in the literature, we attempted to manage our patient with red blood cell transfusions, with no improvement for five weeks, so the patient underwent redo surgery with replacement of both valves and device removal. Unfortunately, no significant epithelization was present on the device (Figure 3). In our opinion, such patients can be managed in two ways: firstly, redo surgery; and secondly, redo catheter-based removal of occluders with reattempts at complete closure [36].

\section{Conclusions}

Surgical transapical catheter-based mitral PVL closure with a purpose-specific device is a safe and clinically effective treatment. With some improvements of the surgical technique as regards the access site and defect closure techniques, outstanding results of this treatment option can be achieved.

\section{Acknowledgments}

We greatly appreciate Dr. Rita Kramena for her very important role and immense input into each procedure.

\section{Conflict of interest}

Dr. Eustaquio Maria Onorato is a Consultant for Occlutech, the manufacturer of the PVL closure device used and described in this manuscript. He also is Co-Principal Investigator for an international, multi-center follow-up study monitoring the efficacy and safety of Occlutech PLD in patients with mitral or aortic PVL. The other authors declare no conflict of interest.

\section{References}

1. Hourihan M, Perry SB, Mandell VS, et al. Transcatheter umbrella closure of valvular and paravalvular leaks. J Am Coll Cardiol 1992; 20: 1371-7.

2. Ruiz CE, Hahn RT, Berrebi A, et al. Clinical trial principles and endpoint definitions for paravalvular leaks in surgical prosthesis: an expert statement. Eur Heart J 2017; 69: 2067-87.

3. Calvert PA, Northridge DB, Malik IS, et al. Percutaneous device closure of paravalvular leak: combined experience from the United Kingdom and Ireland. Circulation 2016; 134: 934-44.

4. Lampropoulos K, Aggeli C, Megalou A, et al. Diagnosis and treatment of left-sided prosthetic paravalvular regurgitation. Cardiology 2016; 133: 27-34.

5. Smolka G, Pysz P, Kozlowski M, et al. Transcatheter closure of paravalvular leaks using a paravalvular leak device - a prospective Polish registry. Adv Interv Cardiol 2016; 12: 128-34.

6. De Cicco G, Russo C, Moreo A, et al. Mitral valve periprosthetic leakage: anatomical observations in 135 patients from a multicentre study. Eur J Cardiothorac Surg 2006; 30: 887-91.

7. Pibarot P, Hahn RT, Weissman NJ, Monaghan MJ. Assessment of paravalvular regurgitation following TAVR: a proposal of unifying grading scheme. JACC Cardiovasc Imaging 2015; 8: 340-60.

8. Basch E, Reeve BB, Mitchell SA, et al. Development of the National Cancer Institute's patient-reported outcomes version of the common terminology criteria for adverse events (PROCTCAE). J Natl Cancer Inst 2014; 106: pii: dju244.

9. Mehran R, Rao SV, Bhatt DL, et al. Standardized bleeding definitions for cardiovascular clinical trials: a consensus report from the Bleeding Academic Research Consortium. Circulation 2011; 123: 2736-47.

10. Kidney Disease: Improving Global Outcomes (KDIGO) Acute Kidney Injury Work Group KDIGO Clinical Practice Guideline for Acute Kidney Injury. Kidney Int Suppl 2012; 2: 1-138.

11. Zorinas A, Janusauskas V, Davidavicius G, et al. Fusion of realtime 3D transesophageal echocardiography and cardiac fluoroscopy imaging in transapical catheter-based mitral paravalvular leak closure. Adv Interv Cardiol 2017; 13: 263-8.

12. Smolka G, Pysz P, Ochala A, K et al. Transcatheter paravalvular leak closure and hemolysis - a prospective registry. Arch Med Sci 2017; 13: 575-84.

13. Smolka G, Pysz P, Jasinski M, et al. Multiplug paravalvular leak closure using Amplatzer Vascular Plugs III: a prospective registry. Catheter Cardiovasc Interv 2016; 87: 478-87.

14. Nashef SA, Roques F, Sharples LD, et al. EuroSCORE II. Eur J Cardiothorac Surg 2012; 41: 734-44.

15. Wilson AP, Treasure T, Sturridge MF, Gruneberg RN. A scoring method (ASEPSIS) for postoperative wound infections for use in clinical trials of antibiotic prophylaxis. Lancet 1986; 1: 311-3.

16. Horan TC, Gaynes RP, Martone WJ, et al. CDC definitions of nosocomial surgical site infections, 1992: a modification of CDC defi- 
nitions of surgical wound infections. Am J Infect Control 1992; 20: 271-4.

17. Genoni M, Franzen D, Vogt P, et al. Paravalvular leakage after mitral valve replacement: improved long-term survival with aggressive surgery? Eur J Cardiothorac Surg 2000; 17: 14-9.

18. Miller DL, Morris JJ, Schaff HV, et al. Reoperation for aortic valve periprosthetic leakage: identification of patients at risk and results of operation. J Heart Valve Dis 1995; 4: 160-5.

19. Echevarria JR, Bernal JM, Rabasa JM, et al. Reoperation for bioprosthetic valve dysfunction. A decade of clinical experience. Eur J Cardiothorac Surg 1991; 5: 523-6.

20. Hammermeister K, Sethi GK, Henderson WG, et al. Outcomes 15 years after valve replacement with a mechanical versus a bioprosthetic valve: final report of the veterans affairs randomized trial. J Am Coll Cardiol 2000; 36: 1152-8.

21. Aydin U, Sen O, Kadirogullari E, et al. Surgical transapical approach for prosthetic mitral paravalvular leak closure: early results. Artif Organs 2017; 41: 253-61.

22. Smolka G, Pysz P, Jasinski M, et al. Transapical closure of mitral paravalvular leaks with use of Amplatzer vascular plug III. I Invasive Cardiol 2013; 25: 497-501.

23. Taramasso M, Maisano F, Latib A, et al. Conventional surgery and transcatheter closure via surgical transapical approach for paravalvular leak repair in high-risk patients: results from a single-centre experience. Eur Heart J Cardiovasc Imaging 2014; 15: 1161-7.

24. Nijenhuis VJ, Swaans MJ, Post MC, et al. Open transapical approach to transcatheter paravalvular leakage closure: a preliminary experience. Circ Cardiovasc Interv 2014; 7: 611-20.

25. Jelnin $\mathrm{V}$, Dudiy $\mathrm{Y}$, Einhorn BN, et al. Clinical experience with percutaneous left ventricular transapical access for interventions in structural heart defects a safe access and secure exit. JACC Cardiovasc Interv 2011; 4: 868-74.

26. Rucinskas K, Janusauskas V, Zakarkaite D, et al. Off-pump transapical implantation of artificial chordae to correct mitral regurgitation: early results of a single-center experience. J Thorac Cardiovasc Surg 2014; 147: 95-9.

27. Sorajja P, Cabalka AK, Hagler DJ, Rihal CS. Percutaneous repair of paravalvular prosthetic regurgitation: acute and 30-day outcomes in 115 patients. Circ Cardiovasc Interv 2011; 4: 314-21.

28. Ruiz CE, Jelnin V, Kronzon I, et al. Clinical outcomes in patients undergoing percutaneous closure of periprosthetic paravalvular leaks. J Am Coll Cardiol 2011; 58: 2210-7.

29. Nietlispach F, Johnson M, Moss RR, et al. Transcatheter closure of paravalvular defects using a purpose-specific occluder. JACC Cardiovasc Interv 2010; 3: 759-65.

30. Ruiz CE, Chi-Hion L, Vladimir J, et al. Hopscotch technique: a novel method for percutaneous closure of paravalvular leaks. Catheter Cardiovasc Interv 2017; 89: 944-50.

31. Rogers ML, Duffy JP. Surgical aspects of chronic post-thoracotomy pain. Eur J Cardiothorac Surg 2000; 18: 711-6.

32. Landreneau RJ, Wiechmann RJ, Hazelrigg SR, et al. Effect of minimally invasive thoracic surgical approaches on acute and chronic postoperative pain. Chest Surg Clin N Am 1998; 8: 891-906.

33. Czesla M, Gotte J, Weimar T, et al. Safeguards and pitfalls in minimally invasive mitral valve surgery. Ann Cardiothorac Surg 2013; 2: 849-52.

34. Pate GE, Al Zubaidi A, Chandavimol M, et al. Percutaneous closure of prosthetic paravalvular leaks: case series and review. Catheter Cardiovasc Interv 2006; 68: 528-33.
35. Kliger C, Eiros R, Isasti G, et al. Review of surgical prosthetic paravalvular leaks: diagnosis and catheter-based closure. Eur Heart J 2013; 34: 638-49.

36. Hein R, Wunderlich N, Robertson G, et al. Catheter closure of paravalvular leak. Eurolntervention 2006; 2: 318-25. 